\title{
District-level mineral survey using airborne hyperspectral data, Los Menucos, Argentina
}

\author{
Fred A. Kruse $\left({ }^{1}\right)$, Sandra L. Perry $\left({ }^{2}\right)$ and Alejandro Caballero $\left({ }^{3}\right)$ \\ $\left({ }^{1}\right)$ Horizon GeoImaging, LLC, Frisco, Colorado, U.S.A. \\ ${ }^{2}{ }^{2}$ Perry Remote Sensing, LLC, Englewood, Colorado, U.S.A. \\ $\left(^{3}\right)$ Rio Tinto Mining \& Exploration Ltd., Santiago, Chile
}

\begin{abstract}
The Los Menucos District, Rio Negro, Argentina, provides an excellent case history of a complex epithermal gold system mapped and explored using a combination of field mapping and multispectral/hyperspectral remote sensing. The district offers a host of argillic and advanced argillic alteration minerals at the surface, many of which are difficult to identify visually. A strategy utilizing regional targeting with Landsat TM to optimize field mapping followed by district-level survey with hyperspectral imaging (HSI) data demonstrates the value added by high-spectral resolution aircraft data. Standardized analysis methods consisting of spatial and spectral data reduction to a few key endmember spectra provides a consistent way to map spectrally active minerals. Minerals identified in the Los Menucos district using the JPL Airborne Visible/Infrared Imaging Spectrometer (AVIRIS) include hematite, goethite, kaolinite, dickite, alunite, pyrophyllite, muscovite/sericite, montmorillonite, calcite, and zeolites. Hyperspectral maps show good correspondence with the results of field reconnaissance verification and spectral measurements acquired using an ASD field spectrometer. Further analysis of Hyperion (satellite-based) hyperspectral data indicates that similar mapping results can be achieved from satellite altitudes. These examples illustrate the high potential of hyperspectral remote sensing for geologic mapping and mineral exploration.
\end{abstract}

Key words hyperspectral imaging (HSI) - mineral mapping - AVIRIS - EO-1 Hyperion

\section{Introduction}

Hyperspectral remote sensing, measuring hundreds of spectral bands from aircraft and satellite platforms, provides unique spatial/spectral datasets for analysis of surface mineralogy (Goetz et al., 1985; Kruse et al., 2003). These data allow mapping of key iron mineralogy

Mailing address: Dr. Fred A. Kruse, Horizon GeoImaging, LLC, P.O. Box 4279, Frisco, Colorado 80443, U.S.A.; e-mail: kruse@hgimaging.com such as hematite, goethite, and jarosite as well as alteration minerals such as kaolinite, dickite, alunite, and sericite (Clark et al., 1990). Their use for geologic applications is well established (Goetz et al., 1985; Kruse et al., 1999, 2003; Rowan and Mars, 2003).

The Los Menucos, Rio Negro, Argentina, site (fig. 1) is a fossil analog of hot springs similar to modern systems in other locations around the world. This area has the largest significant concentration of advanced argillic, altered Permian ignimbrite and rhyolite assemblages in Argentina (Franco et al., 2000). Alteration is related to the intrusion of Triassic-age (?) rhyolite dome complexes below thick Permian-age felsic volcanic rocks. Associated with dome fields are large areas of phreatic breccias and hematiterich altered oxidized zones. Alteration is charac- 


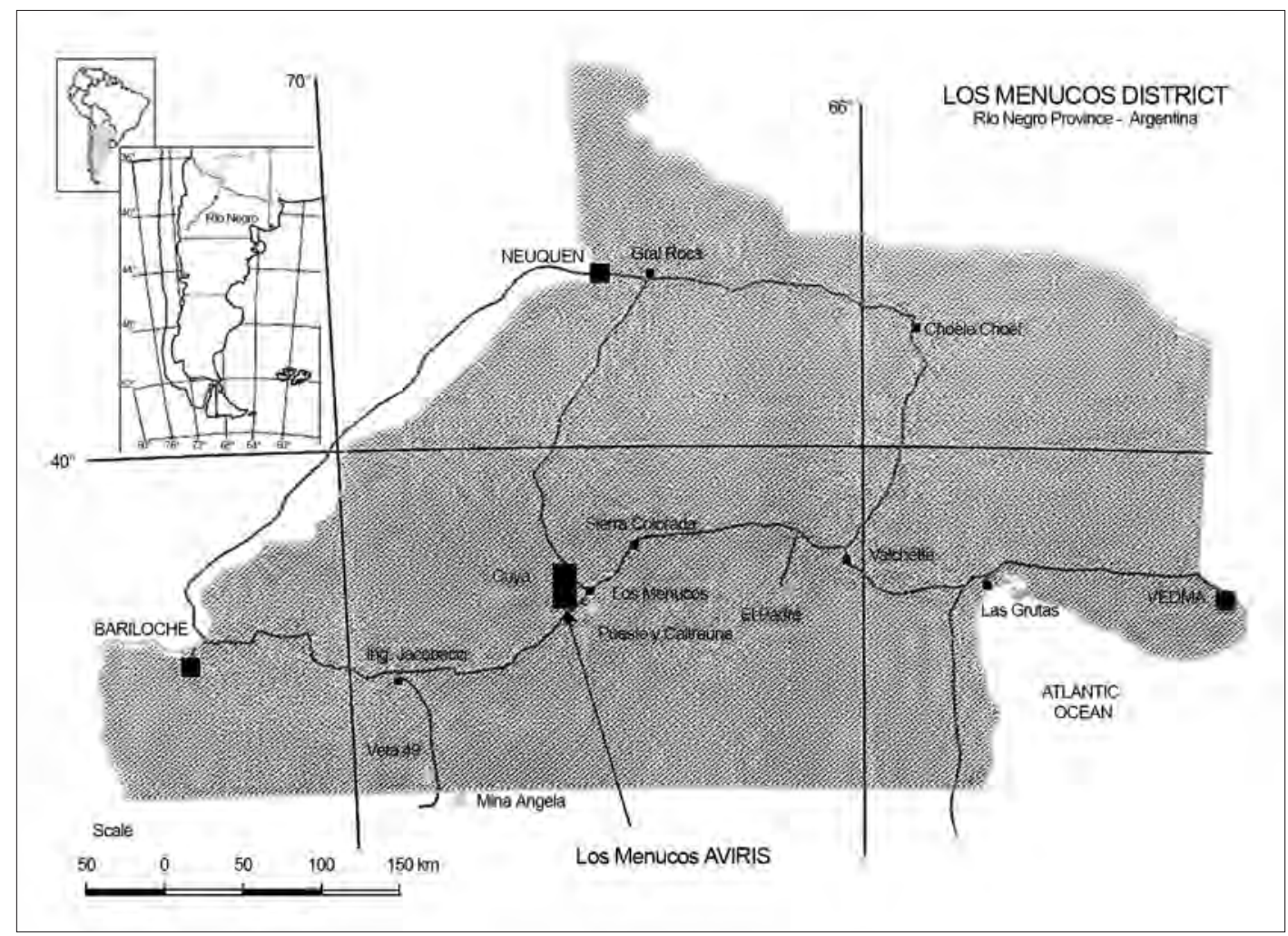

Fig. 1. Los Menucos, Argentina Site Location in Rio Negro province, Argentina. Black box marks approximate extent of AVIRIS survey conducted during February 2001.

terized by vuggy silica, quartz stockwork, kaolin, and alunite. The Los Menucos gold district, with potential for low-sulfidation style gold mineralization, was discovered in 1998 by Arminex, S.A. using regional exploration methods employing Landsat Thematic Mapper (TM) satellite imagery and field investigation (Gemuts and Perry, 2000; Perry and Gemuts, 2000). Over 100 sites were predicted as alteration anomalies resulting from digital enhancement of the Landsat TM imagery analyzed by Perry Remote Sensing, LLC (PRS). These results were used to drive field exploration, and in less than one year, a field crew of six geologists systematically visited and sampled all of these anomalies. Eighty percent of the areas visited exhibited epithermalstyle alteration, and five percent were mineral- ized (Perry and Gemuts, 2000). The exploration effort led Arminex to assemble 80000 ha near the village of Los Menucos and established the area as the first gold district in Rio Negro province. Early in 2000, Rio Tinto Mining \& Exploration (RTZ) took an option on the Arminex property and agreed to continue drilling and testing at key prospect areas. Based on this work, the Los Menucos region was submitted and selected as a NASA E0-1 collection site during 2000 to evaluate Earth observation sensors, including hyperspectral (Airborne Visible/Infrared Imaging Spectrometer (AVIRIS) and satellite EO-1 Hyperion) as well as multispectral data sets (Landsat 7 Enhanced Thematic Mapper and ASTER imagery). TM reconnaissance results are published in Perry and Gemuts (2000). 
Initial AVIRIS results are summarized in Kruse et al. (2002a). An overview of the results of the combined TM reconnaissance and AVIRIS analysis are presented in Kruse et al. (2002b). Preliminary Hyperion, ETM and ASTER results are presented in Kruse et al. (2002c). Additional Hyperion results are summarized in Kruse et al. (2002a,d). Additional details and results for the AVIRIS and Hyperion data analysis are discussed here.

The principal airborne hyperspectral remote sensing instrument used for this research was the Airborne Visible/Infrared Imaging Spectrometer (AVIRIS), a 224-channel hyperspectral sensor with approximately $10 \mathrm{~nm}$ spectral resolution covering the $0.4-2.5 \mu \mathrm{m}$ spectral range (Porter and Enmark, 1987; Green et al., 2003). AVIRIS was flown by NASA/Jet Propulsion Laboratory (JPL) over the Los Menucos District on a Twin Otter aircraft at low altitude on 14-15 February 2001. An AVIRIS dataset was collected consisting of 6 overlapping flightlines (98 «scene» equivalents), covering an area approximately $11 \mathrm{~km} \times 30 \mathrm{~km}$ at $3.5 \mathrm{~m}$ spatial resolution. These data are used to illustrate hyperspectral analysis methods and specific analysis results for the Los Menucos District.

\section{Methods}

A «standardized» hyperspectral data analysis methodology (fig. 2) has been tested for a variety of data (Boardman et al., 1995; Kruse et al., 1999, 2003). This approach is implemented and documented within the «Environment for Visualizing Images» (ENVI) software system originally developed by AIG scientists (now a Research Systems (RSI) CommercialOff-The-Shelf (COTS) product) (RSI, 2001). This is not the only way to analyze these data, but we have found that it provides a consistent way to extract spectral information from hyperspectral data without a priori knowledge or requiring ground observations. Additional details are available in Kruse et al. (2003). The analysis approach consists of the following steps:

- Correction for atmospheric effects using an atmospheric model «ACORN» (AIG, 2001) (fig. 3).

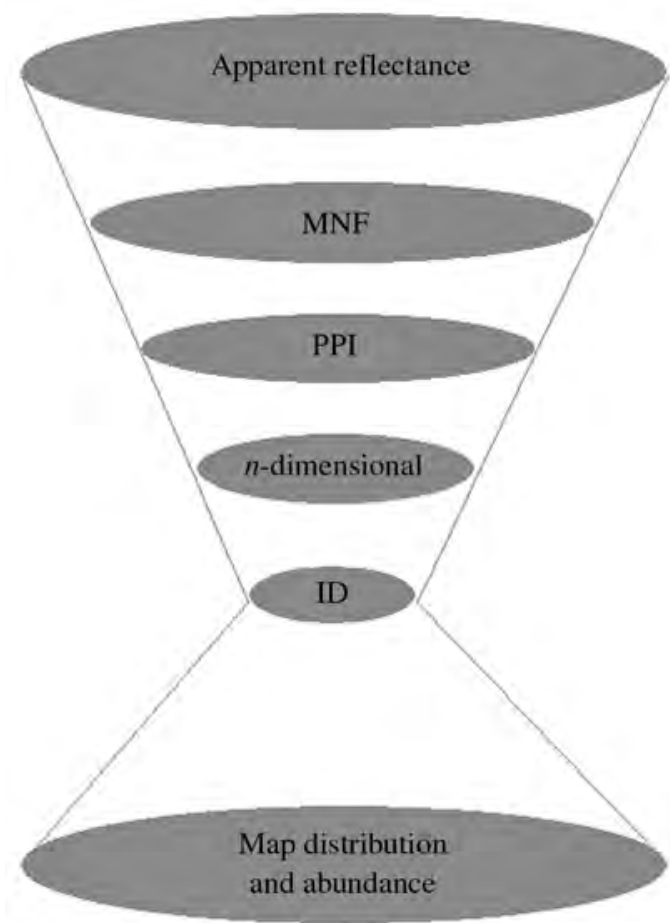

Fig. 2. AIG «hourglass» hyperspectral data processing scheme. Large HSI datasets are reduced to a few key spectra (at the neck of the hourglass) that explain the data using spatial and spectral data reduction techniques (Boardman et al., 1995). Pixel-based spectral mapping methods are then applied to the full HSI dataset.

- Spectral compression, noise suppression, and dimensionality reduction using the Minimum Noise Fraction (MNF) transformation (Green et al., 1988; Boardman, 1993).

- Determination of endmembers using geometric methods (Pixel Purity Index - «PPI») (Boardman and Kruse, 1994; Boardman et al., 1995).

- Extraction of endmember spectra using $n$ dimensional scatter plotting (Boardman et al., 1995).

- Identification of endmember spectra using visual inspection, automated identification, and spectral library comparisons (Kruse and Lefkoff, 1993; Kruse et al., 1993). 

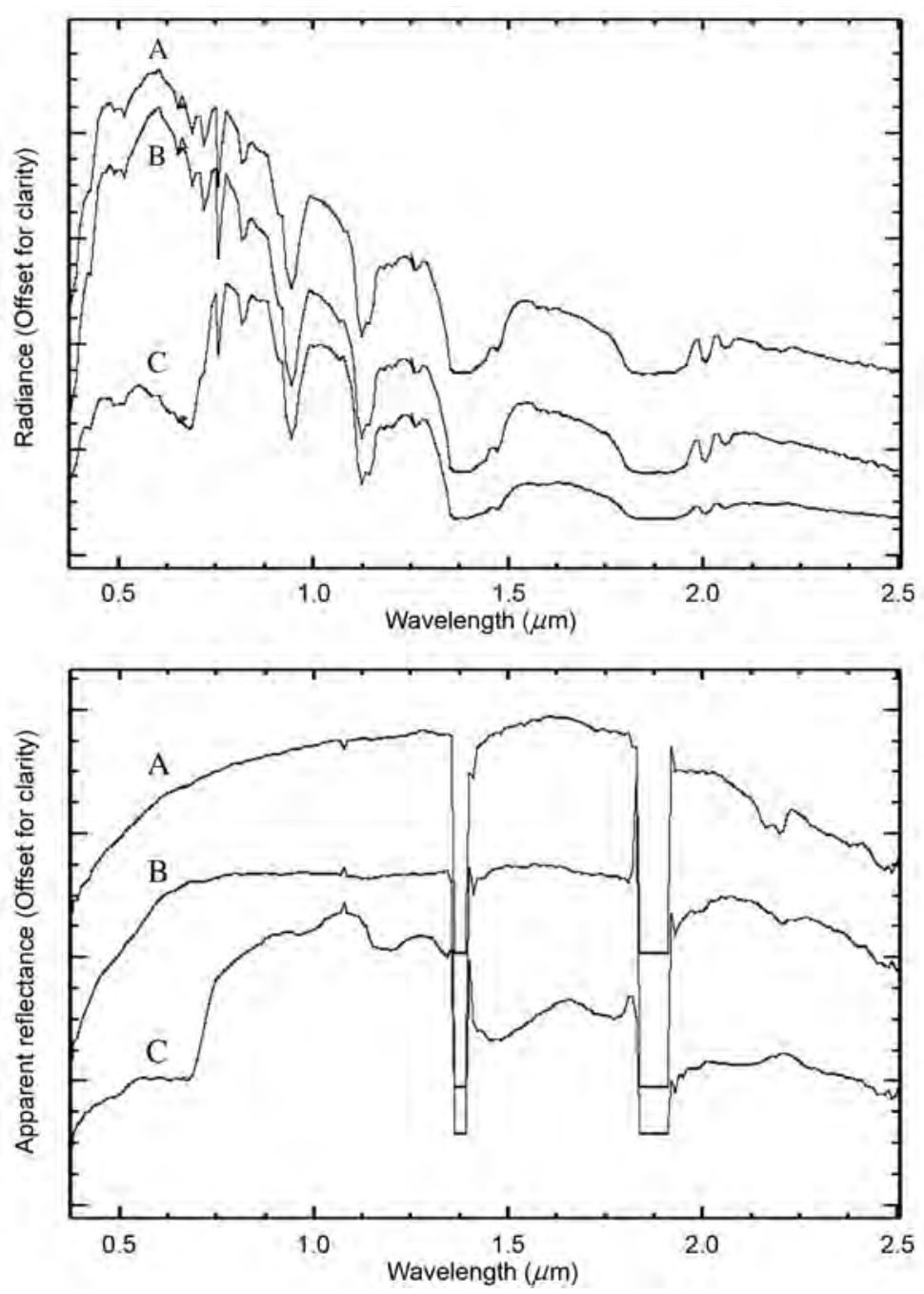

Fig. 3. Comparison of selected AVIRIS radiance spectra (top) and corresponding ACORN reflectance spectra (bottom). Spectrum A is a kaolinite-bearing rock, spectrum B a clay-bearing rock, and spectrum C is green vegetation.

- Production of mineral maps using a variety of mapping methods. «Mixture-Tuned-MatchedFiltering» (MTMF) used for this work is basically a partial linear spectral unmixing procedure (Boardman, 1998).

- Geometric correction of analysis results using sensor models and aircraft or satellite navigation information (Boardman, 1999).

\section{Results}

\subsection{General}

Each of the six AVIRIS flightlines was processed using the above procedures and analyzed separately in reconnaissance mode (optimized for the complete dataset, not individual 
sites), then combined as a spatial mosaic to produce mineral maps of the entire coverage. Two spectral ranges were analyzed; 1) $0.4-1.3 \mu \mathrm{m}$ (iron oxides), and 2) 2.0-2.5 $\mu \mathrm{m}$ (clays, carbonates, etc). The results were map-corrected and combined into an image mosaic covering an approximately $10 \mathrm{~km} \times 30 \mathrm{~km}$ area covering several key mineral prospects. While the complete dataset was analyzed, only Los Menucos AVIRIS flightline \#2, covering several of the

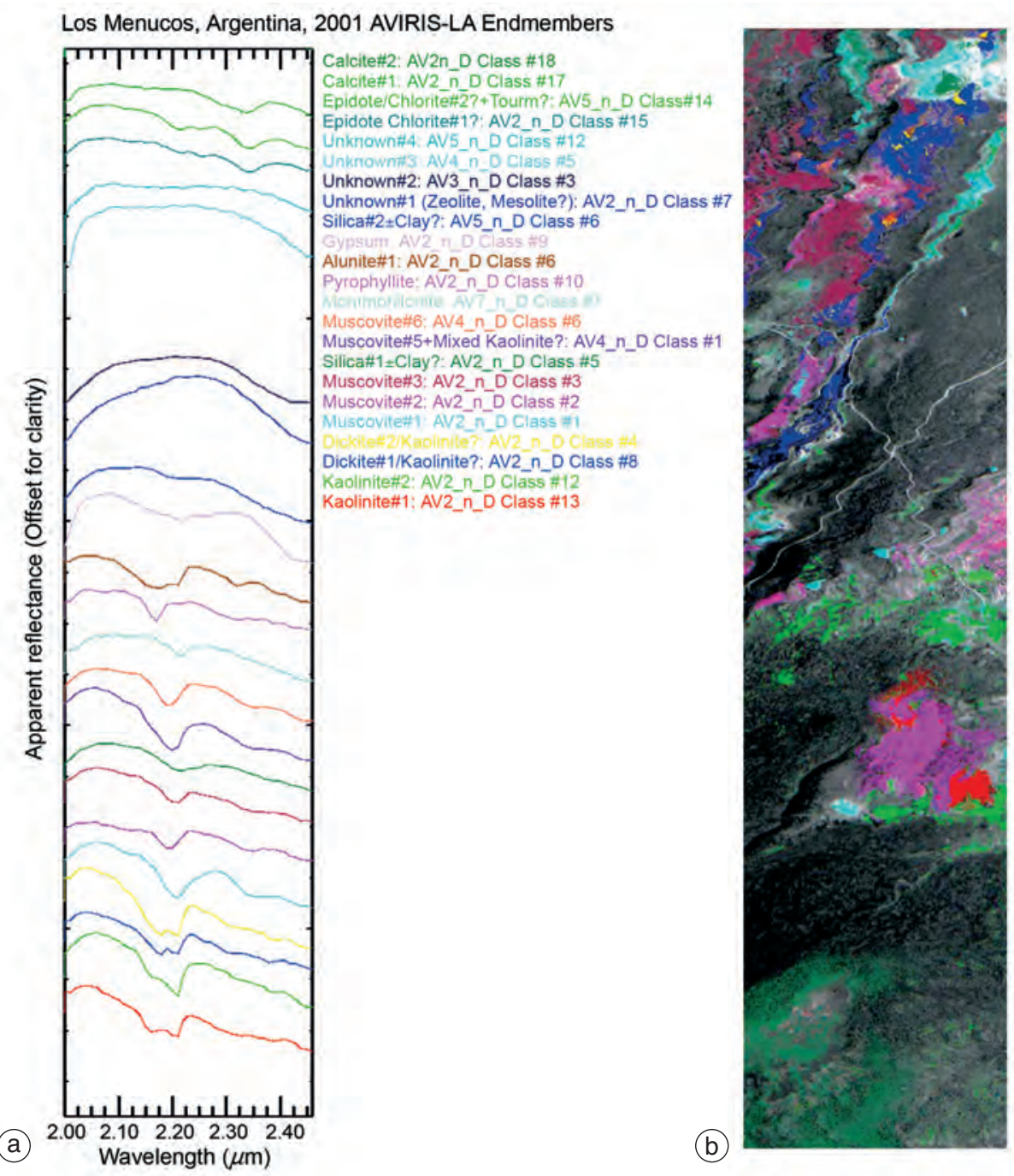

Fig. 4a,b. a) AVIRIS endmember spectra and mapping results for Los Menucos AVIRIS flightline \#2. b) An example of an image-map produced using MTMF for the Los Menucos AVIRIS flightline \#2 SWIR data. MTMF mineral mapping was performed using the endmembers selected and identified using the $n$-dimensional visualization and spectral identification procedures described above and shown in a). MTMF scatterplotting was used to select the spectrally predominant mineral for each pixel at abundances greater than $10 \%$ and to color-code the selected pixels in colors matching the endmember spectra. 
RTZ prospects is shown here as an example of typical AVIRIS processing results using the above methods.

Minerals identified as above for the Los Menucos AVIRIS flightline \#2 SWIR data include several common alteration minerals such as kaolinite, muscovite, alunite, silica, pyrophylite, calcite, montmorillonite, chlorite-epidote, and zeolites (fig. 4a,b). Additionally, because of the high SNR of the AVIRIS data, we were able to discriminate different within-species spectral differences. Thus several varieties of kaolinite and muscovite were also identified (fig. 4a,b).

Field reconnaissance was conducted during April 2001 to validate areas delineated by the AVIRIS analysis. AVIRIS mineral maps were used along with Landsat TM mapping as base maps for field verification. Several prospects and other mineralogically interesting areas were visited, the rocks and alteration were examined, and samples were collected. These samples were analyzed utilizing an Analytical Spectral Devices (ASD) «FieldSpec Full Range» field spectrometer (see http://www.asdi.com) provided by Jet Propulsion Laboratory. The ASD spectrometer covers the $0.35-2.5 \mu \mathrm{m}$ range with approximately $3 \mathrm{~nm}$ (VNIR) and $10 \mathrm{~nm}$ (SWIR) spectral resolution and $1 \mathrm{~nm}$ spectral sampling. A «wand» attachment containing a halogen light source was used to illuminate the samples. This results in a high-quality spectrum with 2151 spectral bands, allowing identification of specific minerals. Over 160 spectral measurements were made of various rocks and soils from the Los Menucos area. Spectral libraries were used to validate and refine AVIRIS results, and to apply to EO-1 Hyperion and Landsat/ASTER multispectral evaluation.

\subsection{AVIRIS Pyrophyllite Discovery}

The AVIRIS data pointed out several minerals and mineral assemblages that were not readily apparent utilizing conventional field mapping methods. In particular, several previously unknown pyrophyllite occurrences cross-cutting predominant structural trends were detected and mapped using the SWIR data (Kruse et al., $2002 a, b)$. These have generated some interest for further exploration. Northwest-trending struc- tures apparently controlled the distribution of both well-crystalline and poorly crystalline kaolinite (fig. 5a,b). Both dickite and pyrophyllite, geochemical indicators of higher temperatures appear to terminate and/or crosscut the kaolinite occurrences (fig. 5b,c). On-the-ground field checking of the pyrophyllite areas showed nothing obvious at these locations. The ground surface was flat, no outcrop was exposed, and it consisted principally of soil with small rock fragments. Map positioning was double checked using GPS and ASD field spectral measurements showed that indeed the principal soil mineral was pyrophyllite (fig. 5d). The spectral signatures, image patterns, and surface exposure indicate that these areas are highly weathered surface exposures of altered rock. Further investigation is required to determine their economic potential.

\subsection{Los Menucos, Argentina Hyperion example}

Hyperion data for the Los Menucos, Argentina, site were first acquired on 25 February 2001, close to the 14-15 February AVIRIS acquisition date. Hyperion is a satellite hyperspectral sensor covering the 0.4 to $2.5 \mu \mathrm{m}$ spectral range with 242 spectral bands at approximately $10 \mathrm{~nm}$ spectral resolution and $30 \mathrm{~m}$ spatial resolution from a $705 \mathrm{~km}$ orbit (Pearlman et al., 1999). Unfortunately, the Hyperion data were predominantly cloudy and because of low solar zenith angle, Signal-to-Noise Ratios (SNR) calculated for this scene were in the 20:1 range, marginal for successful mineral identification and mapping (Kruse et al., 2003). This example, does, however, serve to demonstrate the potential of satellite hyperspectral data for mineral mapping.

The «Cuya» and «Kaolinite Hills» sites shown in fig. 6a-d were mostly clear on the 25 February Hyperion acquisition date. These data were processed to geologic products using the approaches described above for extraction of mineralogic and geologic information. Several characteristic mineral spectra (silica, kaolinite, muscovite) were extracted from the Los Menucos Hyperion data (fig. 6a-d). Mineral maps were produced and compared to those derived from the AVIRIS data above (fig. 6a-d). Com- 

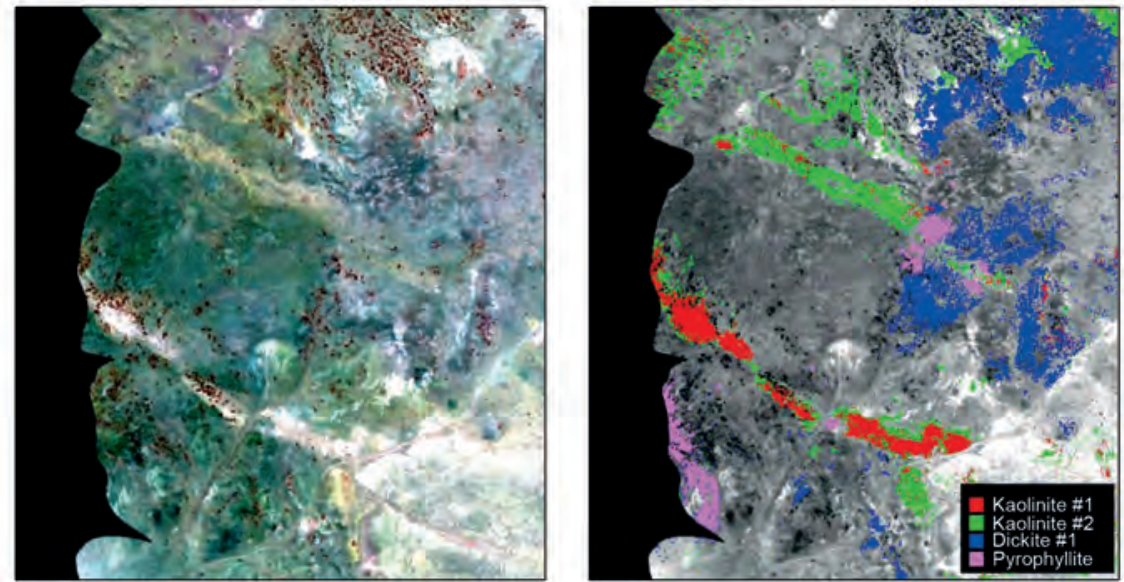

(a)

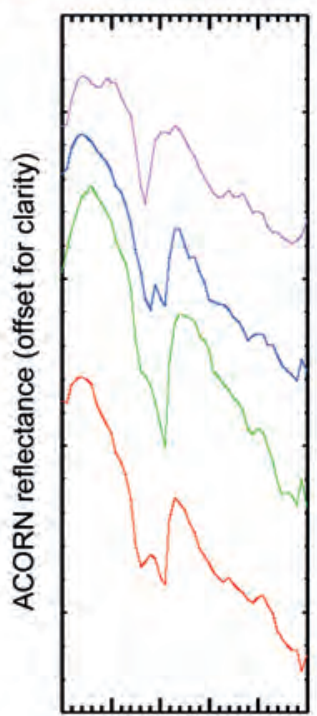

(C)

$\begin{array}{llllll}2.0 & 2.1 & 2.2 & 2.3 & 2.4 & 2.5\end{array}$

Wavelength $(\mu \mathrm{m})$

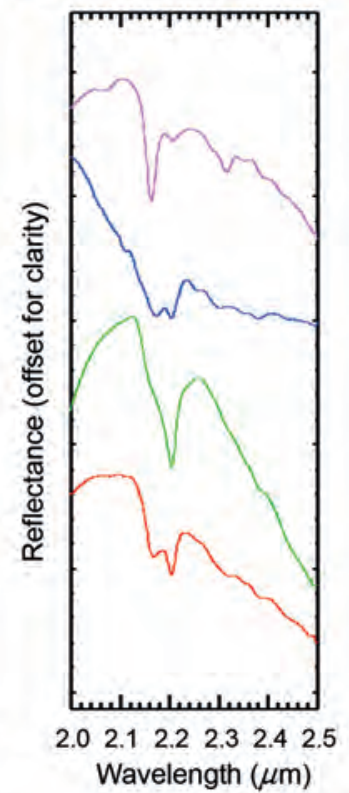

(b)

Fig. 5a-d. Geocorrected Pyophyllite Discovery AVIRIS results. a) False Color Infrared composite (CIR) image of bands 31, 19, $9(0.66,0.55,0.45 \mu \mathrm{m})$ as RGB. b) SWIR mineral mapping results. Note pyrophyllite occurrence in center of image crosscutting northwest-trending kaolinite distributions. c) AVIRIS endmember spectra: red is well crystalline kaolinite, green is poorly crystalline kaolinite, blue is dickite, and orchid is pyrophyllite. d) ASD field spectra for mineral occurrences mapped using AVIRIS. Colors are the same as for the AVIRIS endmembers.

parison of the two datasets shows that Hyperion identifies similar minerals and produces grossly similar mineral mapping results as AVIRIS, however, it does not produce the level of detail available from the AVIRIS data. Some minerals are missed, and others are confused (dickite/kaolinite). The kaolinite doublet shown for AVIRIS data (fig. 6c) is not fully resolved 

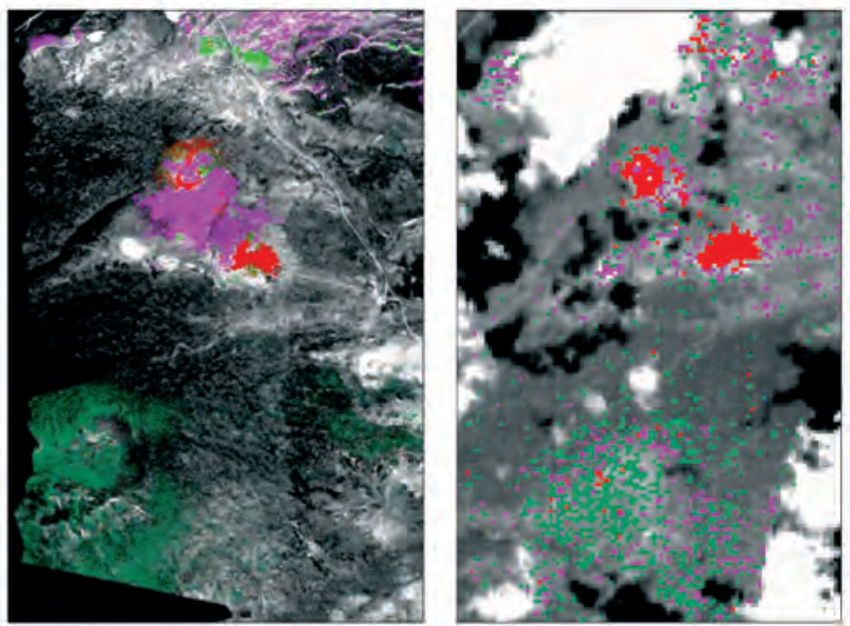

(a)
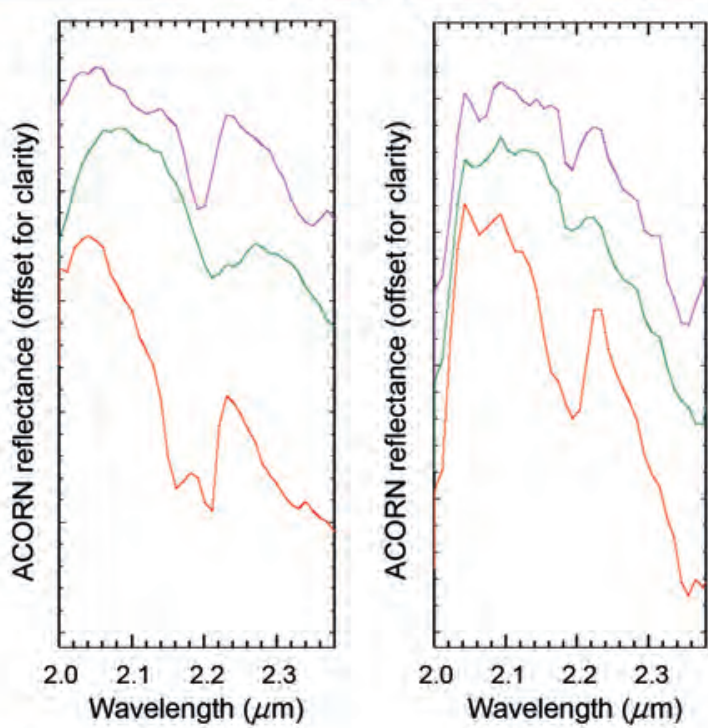

(b)

\section{(C)}

Wavelength $(\mu \mathrm{m})$

(d)

Fig. 6a-d. a) Image-map of selected endmembers from geocorrected AVIRIS SWIR data. Dark green is Cuya area with hydrothermal silica \pm clay signature. Red is Kaolinite Hills area with kaolinite signature. Bright Green area is poorly crystalline kaolinite (spectrum not shown). Magenta shows areas with muscovite signatures. b) Hyperion grayscale image with MTMF mineral map overlay for the same approximate area: colors are the same as for AVIRIS. White areas are clouds and dark areas are cloud shadows. c,d) Hyperion endmember spectra.

by Hyperion (fig. 6d). This is largely the effect of reduced Hyperion signal-to-noise-performance compared to the AVIRIS ( 20:1 and less for these Hyperion data, compared to $>500: 1$ for AVIRIS) (Kruse et al., 2003). The Hyperion data, however, illustrate the potential for worldwide hyperspectral mapping using satellite HSI systems. Suggestions are, that based on improved detector performance and more sophisticated design, that future sensor systems will 
likely approach current AVIRIS mapping performance (R. Green, 2003, pers. comm.).

\section{Discussion and conclusions}

The Los Menucos district AVIRIS case history presented here illustrates the use of hyperspectral data to perform a district-level mineral survey. Initially discovered using Landsat TM multispectral imagery, the district was further mapped and explored using hyperspectral imaging systems (AVIRIS and Hyperion). High-quality, high spatial resolution $(3.5 \mathrm{~m})$ AVIRIS data were the key to rapid assessment of the detailed mineralogy of this area, pointing out minerals and mineral assemblages that were not readily apparent utilizing conventional field mapping methods. Nearly 100 AVIRIS scenes covering an approximately $10 \times 30 \mathrm{~km}$ area were analyzed using standardized HSI analysis methods consisting of spatial and spectral reduction of the hyperspectral data to just a few key endmember spectra. Partial unmixing using Mixture-TunedMatched-Filtering (MTMF) provided a consistent way to process the multiple AVIRIS flightlines allowing identification and mapping of VNIR- and SWIR-active minerals. Common alteration minerals such as hematite, goethite, kaolinite, dickite, alunite, pyrophyllite, muscovite/sericite, montmorillonite, calcite, and zeolites were mapped. Distinguishing between similar minerals such as kaolinite and dickite and mapping of muscovite variability related to cation substitution was possible because of the high SNR of the AVIRIS sensor. AVIRIS mapping results closely agree with field reconnaissance and ground spectral measurements. Analysis of a Hyperion dataset generally validates inorbit mineral mapping and sets the standard for future satellite hyperspectral system performance. These examples illustrate the high potential of hyperspectral remote sensing for geologic mapping and mineral exploration.

\section{Acknowledgements}

This research was partially funded by NASA under grant NCC5-495. Additional fi- nancial support was provided by Analytical Imaging and Geophysics, LLC and Perry Remote Sensing, LLC internal research and development funds. The Argentina test site was suggested by Sandra Perry, Perry Remote Sensing LLC, Englewood, Colorado, U.S.A. Argentina field work and spectral measurements were partially supported by Rio Tinto Mining \& Exploration Ltd., Santiago, Chile, and conducted cooperatively between AIG/PRS/RTZ. AVIRIS data were provided by JPL. Spectral measurements in Argentina were made with JPL's ASD FieldSpec Pro field spectrometer. Hyperion data were provided by NASA, Goddard Space Flight Center as part of the EO-1 Science Validation Team effort. ACORN is a trademark of ImSpec Associates, LLC. ENVI is a registered trademark of Research Systems Inc., Boulder, Colorado. Pixel Purity Index (PPI), and Mixture-Tuned Matched Filter (MTMF) are all trademarks of Research Systems Inc. FieldSpec is a trademark of Analytical Spectral Devices, Boulder, Colorado.

\section{REFERENCES}

AIG (2001): ACORN User's Guide, Stand Alone Version, Analytical Imaging and Geophysics, LLC, p. 64.

BoARDMAN, J.W. (1993): Automated spectral unmixing of AVIRIS data using convex geometry concepts, in Summaries, Fourth JPL Airborne Geoscience Workshop, Jet Propulsion Laboratory Publ. 93-26, 1, 11-14.

BOARDMAN, J.W. (1998): Leveraging the high dimensionality of AVIRIS data for improved sub-pixel target unmixing and rejection of false positives: mixture tuned matched filtering, in Summaries of the Seventh Annual JPL Airborne Geoscience Workshop, Pasadena, CA, Jet Propulsion Laboratory Publ. 97-21, 1, p. 55.

BOARDMAN, J.W. (1999): Precision geocoding of AVIRIS low-altitude data: lessons learned in 1998, in Proceedings of the 8th JPL Airborne Earth Science Workshop, Jet Propulsion Laboratory Publ. 99-17, 63-68.

BoARDMAN, J.W. and F.A. KRUSE (1994): Automated spectral analysis: A geological example using AVIRIS data, northern Grapevine Mountains, Nevada, in Proceedings of the Tenth Thematic Conference, Geologic Remote Sensing, 912 May 1994, San Antonio, Texas, I-407-I-418.

Boardman, J.W., F.A. Kruse and R.O. Green (1995): Mapping target signatures via partial unmixing of AVIRIS data, in Summaries, Fifth JPL Airborne Earth Science Workshop, Jet Propulsion Laboratory Publ. 95-1, 1, 23-26.

Clark, R.N., T.V.V. King, M. KLeJwa and G.A. Swayze (1990): High spectral resolution spectroscopy of minerals, J. Geophys. Res., 95 (B8), 12653-12680. 
Franco, S., N. Puente, C. Varela and I. Gemuts (2000): Mineralizacion aurifera en El Distrito Los Menucos, Provincia de Rio Negro, Argentina, in Proceedings of the Argentina Mining 2000, August 22-25, 2000, Mendoza, Argentina, 112-126.

Gemuts, I. and S. Perry (2000): Los Menucos Au District, Rio Negro Province, Argentina, Abstract and Presentation, Northwest Mining Association, December 7-10, 2000, Spokane, Washington.

Goetz, A.F.H., G. VAne, J.E. Solomon and B.N. Rock (1985): Imaging spectrometry for Earth remote sensing, Science, 228, 1147-1153.

Green, A.A., M. Berman, B. Switzer and M.D. Craig (1988): A transformation for ordering multispectral data in terms of image quality with implications for noise removal, IEEE Trans. Geosci. Remote Sensing, 26 (1), 65-74.

Green, R.O., T.G. Chrien and B. PAVRI (2003): On-orbit determination of the radiometric and spectral calibration of Hyperion using ground, atmospheric and AVIRIS underflight measurements, IEEE Trans. Geosci. Remote Sensing, 41 (6), 1194-1203.

Kruse, F.A. and A.B. LefKoff (1993): Knowledge-based geologic mapping with imaging spectrometers, Remote Sensing Rev., 8, 3-28.

Kruse, F.A., A.B. Lefkoff and J.B. Dietz (1993): Expert system-based mineral mapping in Northern Death Valley, California/Nevada using the Airborne Visible/Infrared Imaging Spectrometer (AVIRIS), Remote Sensing Environ, 44, 309-336.

Kruse, F.A., J.W. BoARdman and J.F. Huntington (1999), Fifteen years of hyperspectral data: Northern Grapevine Mountains, Nevada, in Proceedings of the 8th JPL Airborne Earth Science Workshop, Jet Propulsion Laboratory Publ. 99-17, 247-258.

Kruse, F.A., J.W. BoARDMAN and J.F. HunTINGTON (2002a): Comparison of EO-1 hyperion and airborne hyperspectral remote sensing data for geologic applications, in Proceedings of the IEEE Aerospace Conference, 9-16 March 2002, Big Sky, Montana (CD-ROM), IEEE Cat. No. 02TH8593C, Paper \#6.0102, p. 12.

Kruse, F.A., S.L. Perry and A. Caballero (2002b): Integrated multispectral and hyperspectral mineral mapping, Los Menucos, Rio Negro, Argentina, Part I.
Landsat TM reconnaissance and AVIRIS prospect mapping, in Proceedings of the 11th JPL Airborne Geoscience Workshop, 4-8 March 2002, Pasadena, CA, Jet Propulsion Laboratory Publ. 03-4 (CD-ROM).

Kruse, F.A., S.L. Perry and A. Caballero (2002c): Integrated multispectral and hyperspectral mineral mapping, Los Menucos, Rio Negro, Argentina, Part II. EO1 Hyperion/AVIRIS comparisons and landsat TM/ ASTER extensions, in Proceedings of the 11th JPL Airborne Geoscience Workshop, 4-8 March 2002, Pasadena, CA, Jet Propulsion Laboratory Publ. 03-4 (CDROM).

Kruse, F.A., J.W. Boardman, J.E. Huntington, P. Mason and M.A. QuigLEY (2002d): Evaluation and validation of EO-1 hyperion for geologic mapping, in Proceedings of the IGARSS 2002, 24-28 June 2002, Toronto, Canada, Paper 02_06_17:00 (CD ROM); IEEE Operations Center, Piscataway, NJ, I, 593-595.

Kruse, F.A., J.W. BoARdMAN and J.F. HunTINGTON (2003): Evaluation and validation of EO-1 hyperion for mineral mapping, IEEE Trans. Geosci. Remote Sensing, 41 (6), 1388-1400.

Pearlman, J., S. Carman, P. Lee, L. Liao and C. Segal (1999): Hyperion imaging spectrometer on the new millennium program Earth Orbiter-1 system, in Proceedings of the International Symposium on Spectral Sensing Research (ISSSR), Systems and Sensors for the New Millennium, International Society for Photogrammetry and Remote Sensing (ISPRS), (CD-ROM).

PERrY, S. and I. GEMUTS (2000): New high sulfidation gold district: Los Menucos, Rio Negro Province, Argentina - A landsat discovery, presented at Fourteenth International Conference, Applied Geologic Remote Sensing, November 6-8, 2000, Las Vegas, Nevada.

PORTER, W.M. and H.E. ENMARK (1987): System overview of the Airborne Visible/Infrared Imaging Spectrometer (AVIRIS), SPIE Proc., 834, 22-31.

RowAN, L.C. and J.C. MARS (2003): Lithologic mapping in the Mountain Pass, California area using Advanced Spaceborne Thermal Emission and Reflection Spectrometer (ASTER) data, Remote Sensing Environ., 84, 350-366.

RSI (2001): ENVI User's Guide (Research Systems Inc.), p. 948. 